\title{
Study on the Prevalence of GIT Nematodes on Bovine in and around Kombolcha and Dessie Town, North Eastern, Ethiopia
}

Oumer Abdulkadir ${ }^{1}$, Muhammed Hamid ${ }^{1}$, Alula Alemayehu ${ }^{2}$ and Tarekegn Tintagu ${ }^{2^{*}}$

${ }^{1}$ College of Veterinary Medicine, Semera University, Semera, Ethiopia

${ }^{2}$ School of Veterinary Medicine, Wollo University, Dessie, Ethiopia

*Corresponding author: Tarekegn Tintagu, School of Veterinary Medicine, Wollo University, Dessie, Ethiopia, Tel: 033-311-5204; E-mail: drtarekegn@yahoo.com

Rec date: September 19, 2017; Acc date: September 25, 2017; Pub date: September 26, 2017

Copyright: (c) 2017 Abdulkadir O, et al. This is an open-access article distributed under the terms of the Creative Commons Attribution License, which permits unrestricted use, distribution, and reproduction in any medium, provided the original author and source are credited.

\begin{abstract}
A cross sectional study was carried out from November 2014 to April 2015 to determine the prevalence of bovine gastrointestinal tract (GIT) nematodes and associated risk factors by using flotation technique and fecal culture in and around Kombolcha and Dessie town. Out of 384 bovines examined for GIT nematodes, 160 (41.7\%) animals were found positive for single or mixed GI nematode infection. The findings of fecal examination revealed eggs of Strongyle, Ascaris and Trichuris type were identified. Cattle harboring single-parasite eggs (83.75\%) were more common than those harboring mixed eggs (16.25\%) type. The major nematode genera identified by fecal culture were Oesophagostomum (11.5\%), Bunostomum (7.0\%), Trichuris $(5.5 \%)$, Stronglyloides $(2.6 \%)$, Haemonchus $(2.9 \%)$, Trichostrongylus $(2.6 \%)$, Toxocara $(1.6 \%)$ and Ostertagia $(1.3 \%)$. The prevalence of gastrointestinal nematode infection showed a significant difference $(p<0.05)$ between sex, age, breed, body conditions, management and origin of the animals. In conclusion, the present study has revealed the presence of GIT nematodes which have significant impact on the health and production of the cattle's in the study area. Therefore, further studies on species identification and seasonal epidemiology of these parasites should be carried out.
\end{abstract}

Keywords: Cattle; Dessie; Gastrointestinal nematode; Kombolcha; Prevalence

\section{Introduction}

Ethiopia is endowed with abundant livestock resources of varied and diversified genetic roles with specific adaption to its wide range of agro ecologies. The country is claimed to have the largest livestock population of 47.5 million cattle, 26.1 million sheep 21.7 million goat, 7.8 million equines, 1 million camel, 39.6 million chickens [1].

Gastrointestinal parasite infections are a world-wide problem for both small and large scale farmers, but their impact is greater in subSaharan Africa in general and Ethiopia in particular due to the availability of a wide range of agro-ecological Factors suitable for diversified hosts and parasite species. Economic losses are caused by gastrointestinal parasites in a variety of ways: they cause losses through lowered fertility, reduced work capacity, involuntary culling, a reduction in food intake and lower weight gains, lower milk production, treatment costs, and mortality in heavily parasitized animals [2]. In addition, the diverse agro-climatic conditions, animal husbandry practice and pasture management largely determine the incidence and severity of various parasitic diseases in certain area. Furthermore, the prevalence of gastrointestinal parasites, the genera of helminth parasites involved, species and the severity of infection also vary considerably depending on local environmental conditions such as humidity, temperature, rainfall, vegetation and management practices [3,4].

Some of the major nematodes responsible for gastrointestinal tract parasitosis in ruminants under tropical environment are: Haemonchus, Trichostrongylus, Nematodirus and Ostertagia spp. (Family: Trichostrongylidae); Bunostomum (Ancylostomatidae);
Oesophagostomum spp. (Strongylidae); and Trichuris and Strongyloides spp. [5]. Despite the immense progress made to control parasitosis, farmers in Ethiopia continue to incur significant losses due to insufficient availability of information in the epidemiology of the parasites. Furthermore, parasites appear to be a major factor for lowered productivity of Ethiopian livestock sector [6]. To take the control measures; assessment and epidemiological surveillance of nematode parasite by different diagnostic methods like fecal examination, EPG, determination and identification of specific species nematode is important $[7,8]$. Emphasis must be placed on preventing the environment from becoming contaminated. This is achieved by production of safe pastures which intern achieved by a variety of means like silage and hay after mach, pasture resting, reseeding and burning of pasture and anthelmintic treatment [9].

The prevalence of gastro intestinal nematode in bovine in many African countries including Ethiopia was found to be high. For instance, Awraris et al. (27.57\%), Hiko and Wondimu (54\%) in Gondar town and Haramaya University dairy farm respectively $[8,10]$ whereas Keyyu et al. reported prevalence of $67 \%, 44.4 \%$ and $37 \%$ for traditional, large and small scale dairy cattle, respectively in Tanzania [11]. Furthermore, Pfukenyi et al. and Waruiru et al. and Kabaka et al. reported that gastrointestinal parasites are among the constraints in cattle of Zimbabwe and Kenya, respectively [12-14].

Most of the studies conducted on the prevalence and distribution of GI nematodes in the country tended to be in the central and Northern highlands and semi-arid regions of Eastern Ethiopia. However, the information regarding status of GIT nematodes infecting cattle's in the study area is scanty. Therefore, the objectives of the present study were

- To assess the prevalence of GI nematode parasite of cattle in and around Kombolcha and Dessie town. 
Citation: Abdulkadir O, Hamid M, Alemayehu A, Tintagu T (2017) Study on the Prevalence of GIT Nematodes on Bovine in and around Kombolcha and Dessie Town, North Eastern, Ethiopia. J Vet Sci Technol 8: 477. doi:10.4172/2157-7579.1000477

Page 2 of 5

- To investigate the main risk factors associated with the prevalence of GI nematode infestation in cattle.

\section{Materials and Methods}

\section{Study area}

The study was conducted from November 2014 to April 2015 in Kombolcha and Dessie town which is found in Amhara regional state south Wollo zone, North east Ethiopia. They are found 380-401 Km away from Addis Ababa. It has a latitude and longitude of $1104 \mathrm{~N} 390$ $44 \mathrm{E}$ and $11.060 \mathrm{~N}, 39.7330 \mathrm{E}$ and its elevation is between 1500- 2600 meter above sea level (masl). The topography of south wollo zone is marked by the presence of numerous mountains, plateaus, hilly and sloppy areas, rivers and lakes. The area is characterized by bimodal rain fall with the average rain fall of $6000 \mathrm{~mm}$ and the minimum and maximum temperature varies $11.7^{\circ} \mathrm{C}$ to $24^{\circ} \mathrm{C}$ and the soil type of the area consists of vertisoil and sandy type of soil with vegetation type which varies from larger tree to bushes [1].

\section{Study population}

The study animal were 384 cattle of two breed (150 cross and 234 local breeds), both sexes (194 male and 194 female), Body condition score was made according to Nicolson and butter worth and recorded as poor, medium or good [15]. The age of the animal was estimated by looking to the dentition pattern of the animals according to DeLahunta and Habel and also by owners' response. Based on this, study animals were classified as calf ( $<1$ year), young ( 1 to 3 years) and adult $(>3$ years) $[10]$.

\section{Study design}

A cross-sectional study was carried out from November 2014 to April 2015 to determine the prevalence of bovine nematodes.

\section{Sampling method and sample size}

Simple random sampling technique was employed to select the study animals and feces were collected from the individual animals. The total number of cattle required for the study was calculated based on the formula given by Thrusfield [16]. By rule of thumb where there is no information for an area, it is possible to take $50 \%$ prevalence. In this study $50 \%$ prevalence with $5 \%$ desired level of precision and $95 \%$ of confidence interval are used to calculate the sample size using the following formula.

$$
\mathrm{N}=\left[1.96^{2} \mathrm{P}_{\exp }\left(1-\mathrm{P}_{\exp }\right)\right] / \mathrm{d}^{2}
$$

Where: $\mathrm{N}=$ sample size; $\mathrm{P}_{\exp }=$ expected prevalence; $\mathrm{D}=$ Desired absolute precision; Then by taking $\mathrm{P}_{\exp }=50 \%$ and $\mathrm{d}=5 \% \mathrm{~N}=1.96^{2} \times 0.5$ $(1-0.50) / 0.05 ; \mathrm{N}=384$

\section{Study methodology}

Fecal sample collection: Fecal sample was collected from rectum from each animal using sterile disposable plastic glove. The sample were placed in a labeled clean plastic container (universal bottle) and were transported to the parasitological laboratory of Kombolcha Animal Health and Diagnostic Center on the same day of collection and were preserved at refrigerator until processing within 48 hours of arrival. During every sampling of study animal information on sex, breed, and approximate age of individual animals, body condition, management, owners name, origin and date of collection were recorded.

Coproscopic examination: For coproscopic examination of the fecal samples, a simple test tube flotation technique was employed and the slides prepared were examined under binocular microscope (x10) by Hansen and Perry. Eggs of the different nematodes were identified on the base of morphological appearance and size of eggs [17].

Faecal cultures: Faecal samples from animals of the same species and herd whenever positive for nematode eggs was pooled and cultured for harvesting third stage larvae and identification of the most important genera of non-distinguishable nematode eggs in cattle according to Hansen and Perry [18]. Pooled faecal samples were broken up using stirring device, kept moist and crumbly; the mixtures transferred to petridishes and placed at $27^{\circ} \mathrm{C}$ for 7 to 10 days. The samples were kept humid, mixed occasionally and be aerated every 1-2 days. During this period the larvae was hatched from the eggs and developed into L3. Finally larvae were recovered using the Baermann technique. From each culture, the third-stage larvae (L3) was morphologically differentiated and identified according to keys provided [18].

\section{Data analysis and management}

Data collected from field were entered into Microsoft excel spread sheet (Microsoft Corp.) The data were analyzed by SPSS version 16 statistical packages for window7. Descriptive statistics and chi square were used to describe the prevalence of GIT nematodes and association of risk factors with GIT nematode infection and odd ratio was used to determine the strength. In all the analysis, confidence level held at $95 \%$ and $\mathrm{P}$ value is less than 0.05 considered as significant

\section{Results}

\section{Overall prevalence}

Out of 384 bovine examined 160 (41.7\%) were found positive for GIT nematodes and 8 genera of nematodes in and around Kombolcha and Dessie towns. The highest and lowest percentage of GIT nematodes from different potential risk factors of cattle's were recorded (Table 1).

\section{Association of risk factors with GIT nematodes}

Association of potential risk factors for the occurrence of GIT nematodes were depicted on Table 1. Accordingly, there was a significant association $(\mathrm{P}<0.05)$ in the prevalence of GIT nematodes between sex, age, breed, body condition, management and origin of animals (Table 1 ).

\begin{tabular}{|l|l|l|l|l|l|}
\hline \multicolumn{2}{|l|}{ Variable } & $\begin{array}{l}\text { No of } \\
\text { animals } \\
\text { examined }\end{array}$ & $\begin{array}{l}\text { No } \\
\text { animals } \\
\text { infected with } \\
(\%)\end{array}$ & $X^{2}$ & $\begin{array}{l}\text { P- } \\
\text { value }\end{array}$ \\
\hline \multirow{2}{*}{ Sex } & Male* & 184 & $65(35.3 \%)$ & & \\
\cline { 2 - 7 } & Female & 200 & $95(47.5 \%)$ & 5.843 & 0.016 \\
\hline \multirow{3}{*}{ Age } & Calve* & 30 & $7(23.3 \%)$ & & \\
\cline { 2 - 7 } & Young & 70 & $21(30.0 \%)$ & & \\
\cline { 2 - 7 } & Adult & 284 & $132(46.5 \%)$ & 10.774 & 0.005 \\
\hline
\end{tabular}


Citation: Abdulkadir O, Hamid M, Alemayehu A, Tintagu T (2017) Study on the Prevalence of GIT Nematodes on Bovine in and around Kombolcha and Dessie Town, North Eastern, Ethiopia. J Vet Sci Technol 8: 477. doi:10.4172/2157-7579.1000477

Page 3 of 5

\begin{tabular}{|l|l|l|l|l|l|}
\hline \multirow{3}{*}{ Breed } & Cross & 100 & $28(28.0 \%)$ & & \\
\cline { 2 - 6 } & Local & 284 & $132(46.5 \%)$ & 10.39 & 0.001 \\
\hline \multirow{3}{*}{ BCs } & Good & 94 & $36(27.3 \%)$ & & \\
\cline { 2 - 6 } & Medium & 158 & $65(41.1 \%)$ & & \\
\cline { 2 - 7 } & Poor & 132 & $59(62.8 \%)$ & 28.487 & 0 \\
\hline \multirow{3}{*}{ Origin } & High land & 234 & $50(33.0 \%)$ & & \\
\cline { 2 - 7 } & Mid land & 150 & $110(47.0 \%)$ & 7.033 & 0,008 \\
\hline \multirow{3}{*}{ Mgt } & $\begin{array}{l}\text { Semi } \\
\text { intensive* }\end{array}$ & 98 & $21(21.4 \%)$ & & \\
\cline { 2 - 7 } & Extensive & 286 & $139(48.6 \%)$ & 22.173 & 0 \\
\hline Total & & 384 & $160(41.7 \%)$ & & \\
\hline
\end{tabular}

Table 1: Analysis of the potential risk factors associated with the occurrence of GIT nematodes in cattle at Kombolcha and Dessie town.

\section{Logistic regression analysis of risk factors with GIT nematodes}

Logistic regression analysis of the potential risk factors revealed presence of significant difference in the prevalence of GIT nematodes between sex $(\mathrm{P}=0.016)$, body condition $(\mathrm{P}=0.000)$ and management $(\mathrm{P}=0.000)$ of animals. In line with this female $(\mathrm{OR}=1.839$, $95 \% \mathrm{CI}=1.184-2.857)$, poor body condition $(\mathrm{OR}=2.776$, 95\% $\mathrm{CI}=1.221-6.313)$ and extensive management ( $\mathrm{OR}=2.228$, 95\% CI=1.125-4.416) had higher odds to acquire GIT nematode infections than males, good body condition and semi intensively kept animals respectively. Conversely, statistically significant difference $(P>0.05)$ was not observed for ages, breed and origin of the animals.

\begin{tabular}{|c|c|c|c|c|c|}
\hline \multicolumn{2}{|c|}{ Variable } & \multirow{2}{*}{$\begin{array}{l}\begin{array}{l}\text { No of } \\
\text { animals } \\
\text { examined }\end{array} \\
184\end{array}$} & \multirow{2}{*}{$\begin{array}{l}\begin{array}{l}\text { No of } \\
\text { animals } \\
\text { infected with } \\
\text { (\%) }\end{array} \\
65(35.3 \%)\end{array}$} & \multirow[t]{2}{*}{$x^{2}$} & \multirow[t]{2}{*}{$\begin{array}{l}P \text { - } \\
\text { value }\end{array}$} \\
\hline \multirow{2}{*}{ Sex } & Male* $^{*}$ & & & & \\
\hline & Female & 200 & $95(47.5 \%)$ & 5.843 & 0.016 \\
\hline \multirow{3}{*}{ Age } & Calve $^{*}$ & 30 & $7(23.3 \%)$ & & \\
\hline & Young & 70 & $21(30.0 \%)$ & & \\
\hline & Adult & 284 & $132(46.5 \%)$ & 10.774 & 0.005 \\
\hline \multirow{2}{*}{ Breed } & Cross & 100 & $28(28.0 \%)$ & & \\
\hline & Local & 284 & $132(46.5 \%)$ & 10.39 & 0.001 \\
\hline \multirow{3}{*}{ BCs } & Good & 94 & $36(27.3 \%)$ & & \\
\hline & Medium & 158 & $65(41.1 \%)$ & & \\
\hline & Poor & 132 & $59(62.8 \%)$ & 28.487 & 0 \\
\hline \multirow{2}{*}{ Origin } & High land* & 234 & $50(33.0 \%)$ & & \\
\hline & Mid land & 150 & $110(47.0 \%)$ & 7.033 & 0,008 \\
\hline \multirow{2}{*}{ Mgt } & $\begin{array}{l}\text { Semi } \\
\text { intensive* }^{*}\end{array}$ & 98 & $21(21.4 \%)$ & & \\
\hline & Extensive & 286 & $139(48.6 \%)$ & 22.173 & 0 \\
\hline
\end{tabular}

Total

384

$160(41.7 \%)$

Table 2: Logistic regression analysis of the potential risk factors associated with the occurrence of GIT nematodes in cattle at Kombolcha and Dessie town.

\section{Identification of GIT nematodes}

Outs of 160 positive results identified 134 (83.75\%) animals were infected with single nematode. Among single parasitic infection observed in the present study Oesophagostomum (11.5\%) are the most dominant genera followed Bunostomum (7.0\%) and Trichuris (5.5\%). However, the least nematode infection was observed by Ostertagia (1.3\%) (Table 3).

\begin{tabular}{|l|l|l|}
\hline Parasite & No of positive & Percentage \\
\hline Oesophagostomum & 44 & $11.50 \%$ \\
\hline Bunostomum & 27 & $7.00 \%$ \\
\hline Trichuris & 21 & $5.50 \%$ \\
\hline Strongyloides & 10 & $2.60 \%$ \\
\hline Haemonchus & 11 & $2.90 \%$ \\
\hline Trichostrongylus & 10 & $2.60 \%$ \\
\hline Ostertagia & 5 & $1.30 \%$ \\
\hline Toxocara & 6 & $1.60 \%$ \\
\hline Total & 134 & $83.75 \%$ \\
\hline
\end{tabular}

Table 3: Frequency distribution of single gastro-intestinal Parasites infection identified.

Furthermore, mixed GIT nematode infections were also identified in the present study. Accordingly, out of 160 animals which were found positive for GIT nematodes $26(16.25 \%)$ animals were infected from mixed GIT nematodes. Consequently, Oesophagostomum with Bunostomum 7 (1.8\%), Strongyloides with Oesophagostomum 5 (1.3\%), Oesophagostomum with Haemonchus spp 4 (1.0\%), and Trichostrongylus with Bunostomum spp $4(1.0 \%)$ were identified (Table 4).

\begin{tabular}{|l|l|l|}
\hline Parasites & $\begin{array}{l}\text { No of positive } \\
\text { sample }\end{array}$ & Percentage \\
\hline Trichostrongylus and Haemonchus & 3 & $0.80 \%$ \\
\hline $\begin{array}{l}\text { Oesophagostomum and } \\
\text { Bunostomum }\end{array}$ & 7 & $1.80 \%$ \\
\hline $\begin{array}{l}\text { Ostertagia and Haemonchus and } \\
\text { Haemonchus }\end{array}$ & 3 & $0.80 \%$ \\
\hline $\begin{array}{l}\text { Oesophagostomum } \\
\text { Bunostomum and Trichostrongylus }\end{array}$ & 4 & $1.00 \%$ \\
\hline $\begin{array}{l}\text { Strongyloides } \\
\text { Oesophagostomum }\end{array}$ & 5 & $1.00 \%$ \\
\hline Total & 26 & $1.30 \%$ \\
\hline
\end{tabular}

Table 4: Frequency of mixed GIT nematode infections in cattle. 


\section{Discussion}

The current study revealed an overall prevalence of $41.7 \%$, Gastro intestinal nematode infection of cattle. This result is similar to reports in Zimbabuwe by Pfukenyi et al. reported closer but a little higher prevalence of (43\%) as compared to the present study [12]. In contrast the present study is lower than previous finding by Hiko and Wondimu (54\%) in Haramaya university dairy farm [8] and Waruiru et al. $(85.5 \%)$ in Kiambu district of Kenya but the this study is relatively higher than Awraris et al. (27.57\%) and Kabaka et al. (13.8\%) in Gondar town and Nakuru and Mukurweini districts of Kenya respectively $[13,14]$. This could be attributed to differences in management system, topography, de-worming practices, and climatic condition that favor the survival of infective stage of the parasite.

Statistical analysis has revealed that; there is a significant relation $(\mathrm{P}<0.05)$ between sex of animals and occurrence of GIT nematodes. Accordingly higher prevalence was recorded in females (47.5\%) than in males $(35.3 \%)$ which may be due to differences in exposure to infection as a result of the variation in stocking density (sex ratio), the present study agrees the previous reports of Degefu et al. [19] but contradict the result of Keyyu et al. and Pfukenyi et al. [11,12].

There was a strongly significant association $(\mathrm{P}<0.05)$ between the age of the animal with the risk of infection in which the prevalence of GIT Nematodiasis appeared to follow an age pattern whereby adult animal showed higher proportion of infection (46.5\%) as compared to young animal $(30.0 \%)$ and calve $(23.3 \%)$. This concomitant increase in the prevalence with age of animal could be due to increase in the frequency of contact with age and management factors. This agrees with Bacha and Haftu [20], but disagrees with Awraris et al. [10].

A significant difference $(\mathrm{p}<0.05)$ was also found in variation of degree of infection among different breeds where a higher infection was recorded on local breed cattle (46.5\%) compared to cross breed (28.0\%) cattle which is in line with the finding of Awraris et al. [10]. This may be due to a difference in management system and sample size bias. However, it is in contrary to reports of Bacha and Haftu. But the prevalence of GIT nematode infection in relation to cross breed cattle was lower than the reports of Bacha and Haftu (64.15\%) in west Arsi zone [20]. This variation may be due to the difference in management system between these two areas.

In this study, a significant difference $(\mathrm{P}<0.05)$ was observed in GIT nematode infection in relation to body condition where a higher prevalence of Nematodiasis was recorded in poor body condition $(62.8 \%)$ than medium (41.1\%) and good body condition (27.3\%). This poor body condition might be due to malnutrition, other concurrent disease or the current parasitic infection which lead to poor immunological response to infective stage of the parasite. This finding agrees with Awraris et al. [10] but contradict the finding of Regassa et al. [6].

There was statistically significant association $(\mathrm{P}<0.05)$ between GIT nematode and origin of the animal, the prevalence is high in mid land (47.0\%) as compared to highland (33.0\%) which concur the report of Regassa et al. [6]. However, it contradicts the reports of Pfukenyi et al. [12]. The explanation may be related to different management system in different districts.

In this study, there were strongly significant association $(\mathrm{P}<0.05)$ between GIT nematode and management in which animal reared, extensive management system $(48.6 \%)$ accounts higher proportion of nematode than semi intensive (21.4\%) management system. This study agrees with the reports of Keyyu et al. [11] and Kabaka et al. [14]. This might be due to the fact that cattle are more prone to gastro intestinal nematode infestation when extensively due to contamination of pasture by parasites.

Out of 384 samples examined 160 were found positive. Of these 134 $(83.75 \%)$ had single and $26(16.25 \%)$ had mixed infection with different nematode species. This low prevalence of mixed infection in the study area may be due to immunity of the host, season and Deworming practice. This result agrees with the results of Bacha and Haftu [20].

Among all parasites identified in the current study Oesophagostomum spp have the highest proportion (11.5\%) and followed by Bunostomum (7.0\%) and Trichuris (5.5\%). This result dis agrees with the previous report of Kabaka et al. [14]. According to Kabaka et al. the highest prevalence were seen in Haemonchus (28.1\%), followed by Trichostrongylus (19.5\%), and Oesophagostomum (14.8\%) [14]. This may be due to difference in agro climatic condition of the two areas and difference in the prevalence of this parasite.

In case of Oesophagostomum (11.5\%), this result is similar with the result of Hiko and Wondimu $11 \%$ at Haramaya University dairy farm [8]. This similarity of result due to uniform distribution of Oesophagostomum spp in these two areas. However this result is higher than the result of Bacha and Haftu [20] 1.3\% and slightly lower than the reports of Kabaka et al. [14] and Belem et al. [21] 42.6\% which might be due to difference in de-worming practices and agro climatic condition.

The existence of more than one nematode species in a host has an additive pathogenic effect on the host and the pathogenicity is usually high [22]. In this particular study the prevalence of mixed infection was (16.25\%). Among mixed parasitic infestations observed in current study Oesophagostomum and Bunostomum (1.8\%) were most dominant nematodes in cattle's. This result disagree the previous reports of Bacha and Haftu. According to Bacha and Haftu the highest prevalence seen in west Arsi zone was Oesophagostomum spp with Trichostrongylus spp [20]. This difference could be due to difference in the two agro-ecological zones.

\section{Conclusion and Recommendation}

Gastro-intestinal Nematodiasis are important cattle health problems in the study area with prevalence of 160/384 (41.7\%). The present study was based solely on coproscopic examination and fecal culture for detection of gastrointestinal nematode eggs and larvae; among the eight genera of GIT helminth parasites investigated, Oesophagostomum spp (11.7\%) was found to be the most prevalent parasite in the study area, whereas Ostertagia spp (1.8\%) was the least prevalent gastro-intestinal nematode. Most risk factors such as sex, age, breeds, body condition, origin and management of animal have significant relationship $(\mathrm{p}<0.05)$ with the presence of parasitic infestation. In the current work, the prevalence of mixed infestation with two parasite species in the same host was found to be $26 / 160$ (16.25\%). This high prevalence of gastro intestinal nematode in the study area indicates the disease has a great economic importance and requires a great control and preventive issue. So to minimize the wide spread prevalence of this parasitic problem in the study area the following actions should be taken:

- Biological control of nematodes should be practiced 
Citation: Abdulkadir O, Hamid M, Alemayehu A, Tintagu T (2017) Study on the Prevalence of GIT Nematodes on Bovine in and around Kombolcha and Dessie Town, North Eastern, Ethiopia. J Vet Sci Technol 8: 477. doi:10.4172/2157-7579.1000477

Page 5 of 5

- The use of communal grazing and watering points should have to be reduced as they are the principal means of transmission of parasites from one herd to the other.

- Awareness creation among the livestock owners on the proper management, feeding and use of anthlementics should be performed.

- Further studies are needed to establish the seasonal epidemiology of these parasites.

\section{References}

1. CSA (2009) The Federal Democratic Republic of Ethiopia. Agricultural Sample survey.

2. Lebbie SH, Rey B, Irungu EK (1994) Small ruminant research and Development in Africa. Proceedings of the Second Biennial Conference of the African Small Ruminant Research Network. ILCA: pp: 1-5.

3. Barger IA (1999) The role of epidemiological knowledge and grazing management for helminthes control in small ruminants. Int J Parasitol 29: 41-47.

4. Kassai T (1999) Veterinary Helminthology. Butter Worth-Heine-mann. Linacre House. Jordan Hill, Oxford 225 Wildwood Avenue. p: 260.

5. Troncy PM (1989) Helminthes of Livestock and Poultry in tropical Africa. In: Manual of Tropical Veterinary Parasitology, International.

6. Regassa F, Sori T, Dhuguma R, Kiros Y (2006) Epidemiology of Gastrointestinal Parasites of Ruminants in Western Oromia, Ethiopia. Int J Appl Res Vet Med 4: 51-57.

7. Ashutosh W, Anwar TKR, Singla DL, Eda S, Naveen K, et al. (2011) Prevalence of gastro intestinal helminthes in Cattle and buffaloes in Bikaner, Rajasthan, India. Vet World 4: 417-419.

8. Hiko A, Wondimu A (2013) Occurrence of nematodiasis in Holstein Friesian dairy Breed. J Vet Medic Res 1: 6-10.

9. Soulsby JL (1982) Helminths Arthropods and Protozoa of Domestic Animals. 7th edn. Lea N, Febiger B (eds), Philadelphia, p: 809.

10. Awraris T, Bogale B, Chanie M (2012) Occurrence of Gastro Intestinal Nematodes of Cattle in and Around Gondar Town, Amhara Regional State, Ethiopia. Acta Parasitol Globalis 3: 28-33.
11. Keyyu JD, Kssuku AA, Msalilwa LP, Monrad J, Kyvsgaard NC (2006) Cross-Sectional prevalence of helminth infections in cattle on traditional, small-scale and large- scale dairy farms in Iringa District Tanzania. Vet Res Commun 30: 45-55.

12. Pfukenyi DM, Mukaratirwa S, Willingham AL, Monrad J (2007) Epidemiological studies of parasitic gastrointestinal nematodes, cestodes and coccidia infections in cattle in the Highveld and lowveld communal grazing areas of Zimbabwe. Onderstepoort J Vet Res 74: 129-142.

13. Waruiru RM, Kyvsaard NC, Thamsborg SM, Nansen P, Bogh HO, et al. (2000) Prevalence and intensity of helminth and coccidial infections in dairy cattle in Central Kenya. Vet Res Commun 24: 39-53.

14. Kabaka WM, Gitau GK, Kitala PM, Maingi N, Venleeuwen JA (2013) The prevalence of gastro intestinal nematode infection and their impact on cattle in Nakuru and Makurweini districts of Kenya. Ethiop Vet J 17: 95-104.

15. Nicolson MJ, Butterworth MH (1986) A guide to condition scoring of zebu cattle. Int Livest Centre Africa, Addis Ababa, Ethiopia.

16. Thrusfield M (2005) Veterinary Epidemiology. Blackwell Science Limited, USA, pp: 180-181, 224-225.

17. Foriet W (1999) In Reference Manual of Veterinary Parasitology. 5th edn. Wiley Blackwell, New York, USA, pp: 22-26.

18. Hansen J, Perry B (1994) The Epidemiology, Diagnosis and Control of Helminth Parasites of Ruminants. 2nd edn. Nairobi, Kenya.

19. Degefu H, Abera C, Yohannes M, Tolosa T (2011) Gastrointestinal helminth infections in small-scale dairy cattle farms of Jimma town, Ethiopia. Ethiop J Appl Sci Technol 2: 31-37.

20. Bacha A, Haftu B (2014) Study on Prevalence of Gastro intestinal Nematodes and Coccidian Parasites Affecting Cattle in West Arsi Zone, Oromia Regional State, Ethiopia. J Vet Sci Technol 5: 1-6.

21. Belem AMG, Ouedrago OP, Bessin R (2001) Gastro-intestinal nematodes and cestodes of cattle in Burkina Faso. Biotechnol Agron Soc Environ 5: 17-21.

22. Rahmeto A, Meberahtu G, Solomon M, Fufa A, Alemayehu R (2010) Gastrointestinal nematode infection in small ruminants under the traditional husbandry system during the dry season in southern Ethiopia. Trop Anim Heal Prod 42: 1112-1117. 